\title{
La tecnología aeroespacial al servicio del ambiente
}

\section{The aerospace technology serving to the environment}

\author{
Avid Roman Gonzalez \\ TELECOM ParisTech, 46 rue Barrault, 75013 - Paris, Francia \\ German Aerospace Center - DLR, Remote Sensing Institute, Oberpfaffenhofen 82234 Wessling, Germany \\ Centre National d'Etudes Spatiales - CNES, Francia
}

\section{RESUMEN}

La biodiversidad es un tema que se encuentra hoy en día en el foco de numerosos debates sociales ligados a la relación hombre-ambiente y su impacto directo en la gestión del medio ambiente. En ese sentido, la tecnología aeroespacial juega un papel muy importante. En el presente artículo se presenta de manera general una revisión sobre los factores medioambientales que se deben tener en cuenta y que deben ser monitoreados para la toma de decisiones en aras de una preservación de nuestro ecosistema. También hablaremos de cómo es que la tecnología aeroespacial a través de diferentes satélites, ayudan de manera eficaz y casi en tiempo real con esta difícil tarea.

Descriptores: ambiente, satélites, tecnología aeroespacial, monitorización, imágenes satelitales.

\section{ABSTRACT}

Biodiversity is an issue that is now the focus of many social debates linked to the man-environment interaction and its direct impact on environmental management. In that sense, aerospace technology plays an important role. This article presents a general review of environmental factors to be taken into account and should be monitored for take the better decision in the interest of preserving our ecosystem. We also discuss how the aerospace technology through different satellites, help effectively and almost in real time with this difficult task. Keywords: environment, satellites, aerospace technology, monitoring, satellite images.

\section{INTRODUCCIÓN}

De un tiempo a esta parte, el tema del "Medio Ambiente" se ha convertido en un tema de moda, y es que la contaminación, la escasez de agua y el calentamiento global, han aumentado, los nevados se están derritiendo, algunas especies de flora y fauna se están extinguiendo y el pulmón del mundo (la amazonia) se está reduciendo por culpa de la tala no controlada y la minería informal. Investigaciones basadas en desarrollo durable son las más esperadas, tales como desarrollo de vehículos utilizando energías renovables para reducir la contaminación, etc
Después de la conferencia de Rio de janeiro en 1992, la biodiversidad se ha convertido en un tema que involucra a la sociedad entera y uno de los mayores problemas en cuanto a desarrollo durable se refiere. La biodiversidad es un elemento esencial de la actividad, la nutrición y la salud de la humanidad. Hoy en día, el equilibrio fundamental del ecosistema parece ser frágil. La toma de conciencia es unánime y el compromiso por hallar una solución está en el horizonte de todos. 


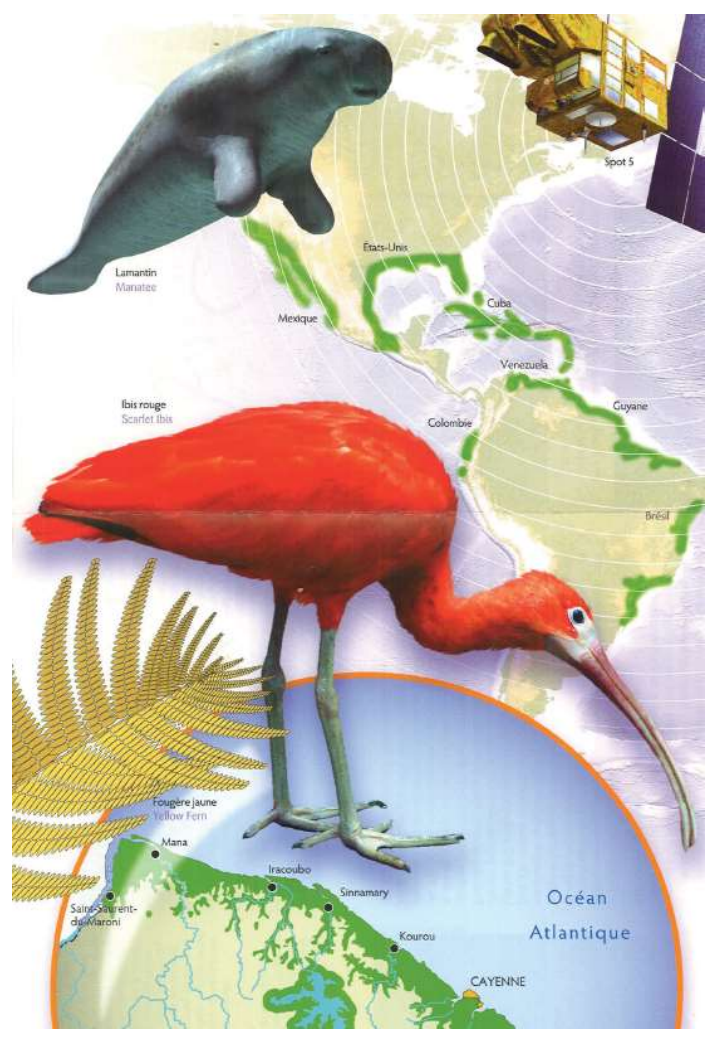

Figura 1. Tecnología Aeroespacial al Servicio del Medio Ambiente [3]

El intercambio de herramientas apropiadas se hace necesario. Es esencial contar con instrumentos de medición a diferentes escalas para monitorear y controlar la dinámica del ecosistema, de esta manera poder conocerla y protegerla mejor.

La tecnología aeroespacial pone todos sus medios (la teledetección, el acceso a la base de datos o la integración de datos a modelos numéricos) a disposición de los poderes públicos para ayudar a la toma de decisiones.

La teledetección puede jugar diferentes papeles. Sirve como herramienta para recolectar, generar y compartir información sobre la zona de captación y/o los recursos hídricos transfronterizos (ríos, lagos, etc.), etc.

El presente artículo está estructurado de la siguiente manera: en la Sección II se presenta una visión general de los océanos y la tierra así como algunas misiones sobre ellas. La Sección III muestra cómo se gestiona los recursos y las catástrofes. La Sección IV presenta la prevención de riesgos a través de la meteorología. La Sección $\mathrm{V}$ presenta algunas aplicaciones actuales de la tecnología aeroespacial aplicado a la monitorización del medio ambiente. Finalmente se puede en encontrar las conclusiones en la Sección VI.

\section{CONOCIENDO LOS OCEANOS Y LA TIERRA}

\section{A. Océanos}

Sabemos que el agua recubre aproximadamente el $70 \%$ de la superficie de la Tierra. Es en lo profundo de estas aguas que la vida apareció antes de salir a la superficie. Miles de millones de años después, una forma de vida, la especia humana, suficientemente inteligente como para tomar consciencia y gracias a los instrumentos espaciales que el mismo desarrollo, desea analizar su impacto sobre el ecosistema.

Una de las primeras preocupaciones ligadas a los océanos con respecto al cambio climático, es el aumento del nivel de agua. Desde el 2005, ciertas poblaciones de Nueva Guinea han sido evacuadas [1]. Estas evacuaciones son por el momento solo de algunas centenas de personas, pero la cantidad al 2050 puede aumentar a centenas de millones de habitantes, ya que alrededor de 600 millones de personas viven cerca de las costas en el mundo entero a menos de 10 metros sobre el nivel del mar [1]. Es por ello que los satélites de altimetría juegan un papel importantísimo. La medida que estos satélites brindan, nos revela que entre 1993 y 2003 el nivel promedio de los océanos se ha elevado a una tasa de $3 \mathrm{~mm}$ por año, en algunos lugares se ha alcanzado el máximo de $2 \mathrm{~cm}$ por año [1]

Este promedio de elevación puede ir en proceso de aceleración, lo cual solo puede ser verificado de manera global gracias a la serie de medidas de los satélites. 


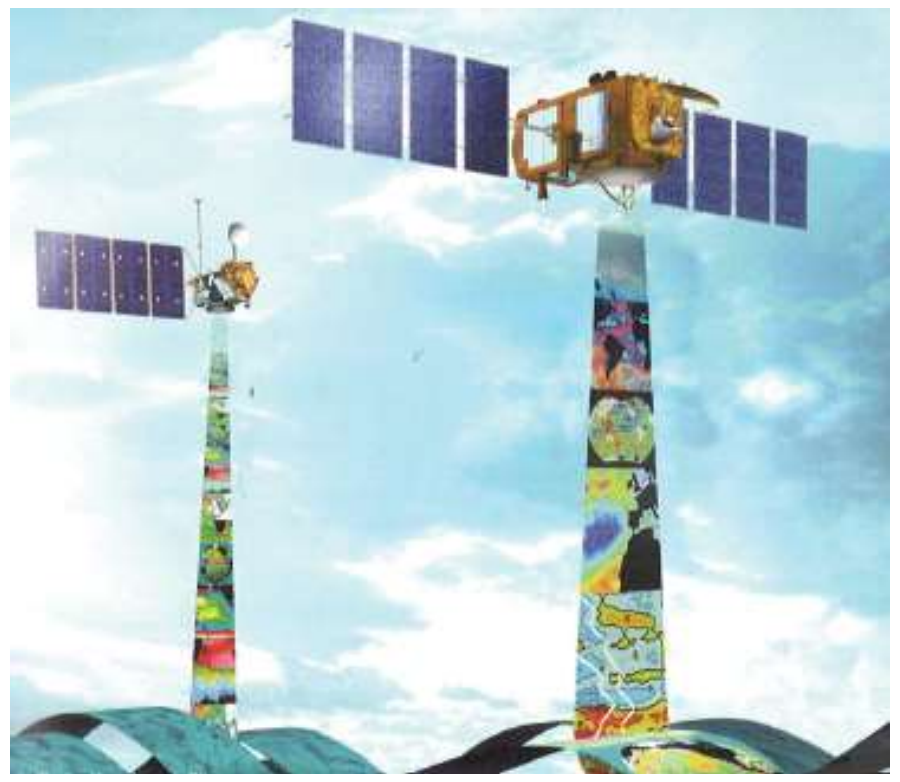

Figura 2. Medida sobre los Océanos a partir de Tecnología Aeroespacial [1]

El Centro Nacional de Estudios Espalciales de Francia (CNES - Centre National d'Etudes Spatiales) es pionero en los satélites de altimetría, lanzando en 1992 el Topex-Poseidon como resultado de una cooperación con la NASA.

La salinidad del agua es otro factor importante que debe ser monitoreado. Mientras más salada sea el agua de los océanos, pues son más densas y tienden a quedarse en el fondo creando en la superficie lo que se llama las aguas calientes provenientes de los trópicos. Este fenómeno es aún más marcado en el Atlántico Norte. Un cambio en un $3 \%$ en la salinidad de las aguas puede causar grandes variaciones en las temperaturas y el calentamiento global. En este contexto la misión SMOS a cargo de la Agencia Espacial Europea ESA en cooperación con el CNES y España, aportan una esperanza a los científicos para ofrecer medidas directas y globales de esta variable.

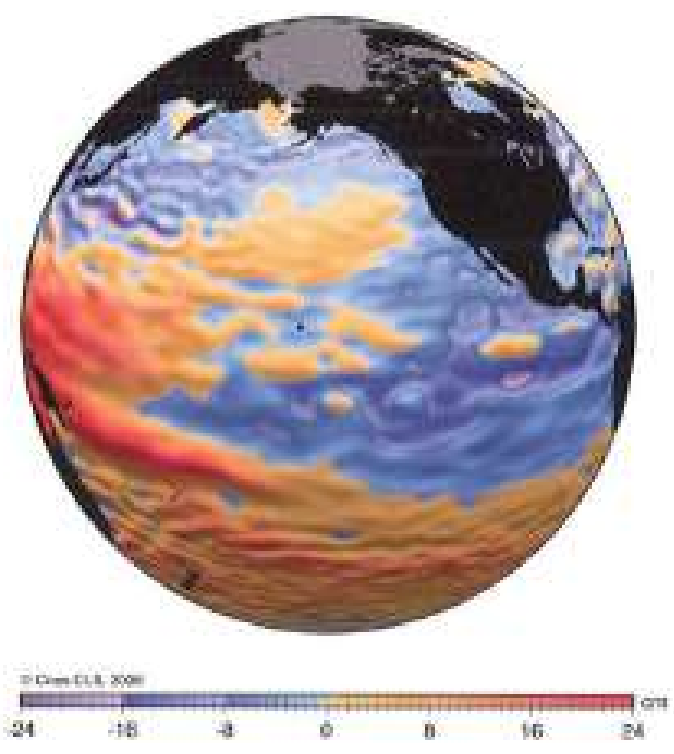

Figura 3. Monitorización del Fenómeno del Niño de 2008 [1]

Otro factor importante es el color del agua, pues el color del agua es un indicador directo de su calidad. Aguas ricas en clorofila revelan una presencia abundante de fitoplancton (primer eslabón de la cadena alimenticia marina). Es en este campo que los satélites son los únicos capaces de dar rápidamente una alerta sobre la degradación de la situación biológica de los océanos.

\section{B. La Tierra}

Entre las principales variables a monitorear en la tierra tenemos: el campo magnético terrestre y el campo gravitatorio.

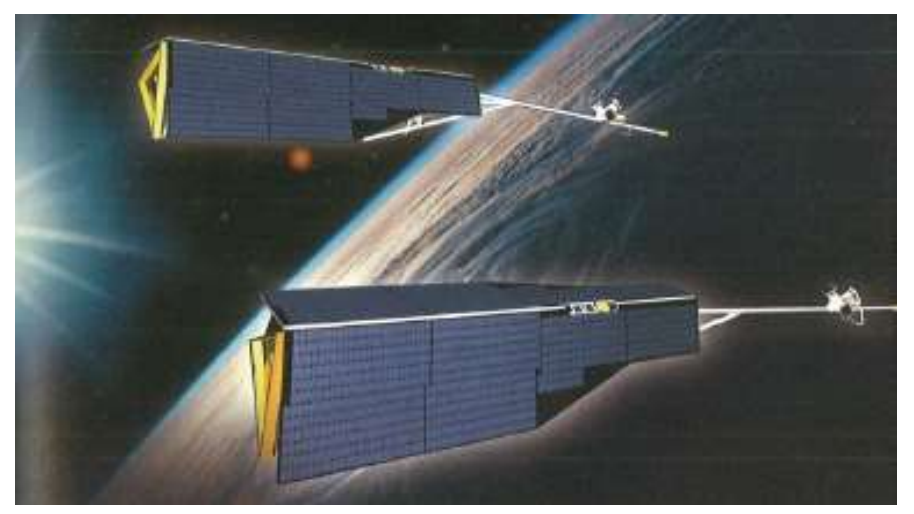

Figura 4. Satélite SWARM [1] 
El campo magnético juega un rol importante en el desarrollo de la vida sobre la tierra, protegiéndonos de partículas cargadas del viento solar y los rayos cósmicos. En un tiempo de 150 años, el campo magnético ha perdido un $15 \%$ de su valor [1]. La misión SWARM fruto de la cooperación entre la ESA y el CNES tiene como objetivo realizar un estudio completo sobre el campo magnético terrestre y su evolución en el tiempo.

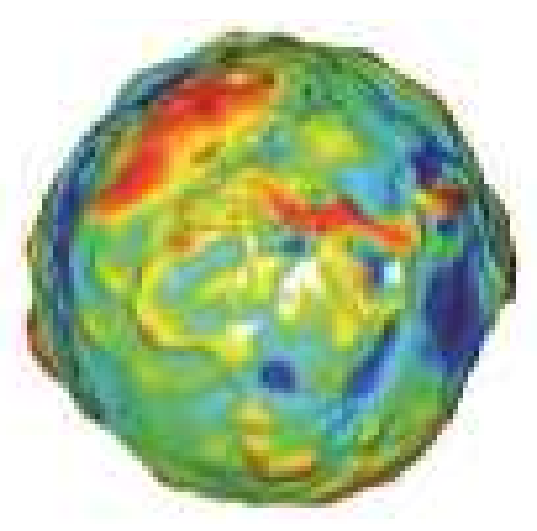

Figura 5. Geoide de la Superficie de la Tierra [1]

El campo gravitatorio de nuestro planeta es el reflejo de la distribución de masas que se concentran en el manto rocoso. Las anomalías ligadas a las superposiciones de las placas tectónicas o a las grandes fallas dejan siempre una huella que puede ser rastreada. El campo gravitatorio también es influenciado por las masas de agua; por ello si estudiamos las variaciones espaciales y temporales del campo gravitatorio, es posible detectar corrientes marinas y la evolución de reservorios de agua.

\section{GESTION DE RECURSOS Y DESASTRES}

Los satélites pueden ofrecer una vista del conjunto de territorios y una cantidad de datos sobre la realidad física del terreno donde se desarrolla el urbanismo o la agricultura.

Hoy en día, los satélites también contribuyen a la realización de cartografías de ciertos indicadores socioeconómicos que eran inaccesibles algunos años atrás.

Las tecnologías aeroespaciales ponen a disposición de los gobernantes, información que permite medir, controlar y organizar el crecimiento de la población urbana, teniendo en cuenta el desarrollo local y sus implicaciones globales.
El CNES es el líder europeo en observación de la Tierra, desde el lanzamiento del satélite Spot 1 en 1986. La resolución de las imágenes ha pasado de 10 o 20 metros para los primeros satélites Spot a 2.5 metros para Spot 5.

\section{A. Utilización razonable de los recursos}

Para el 2050 la población se habrá incrementado en un $30 \%$ aproximadamente [1], y desde ahora el planeta ya muestra algunos signos de dificultad para albergar a toda su población. Es por ello que debemos de hacer un uso razonable de nuestros recursos, pero también debemos gestionar de mejor manera los desechos que producimos.

\section{B. Limitar el impacto de las catastrofes}

En casos de crisis humanitarias, las tecnologías aeroespaciales pueden ofrecer numerosos servicios. Entre las principales ventajas de los satélites tenemos que: Los satélites superan las fronteras, los relieves y las restricciones de acceso a causa del desastre; la cartografía rápida por satélite permite identificar el estado de los lugares y zonas afectadas, para hacer una primera evaluación y enviar dicha información en tiempo real al personal en tierra.

La Carta Internacional "Espacio y Grandes Catástrofes" fue propuesta por la ESA y el CNES en 1999 y firmado en junio de 2000. Tiene por objetivo ofrecer un sistema unificado de adquisición y entrega de datos procedentes de los satélites, cuando se producen catástrofes naturales o humanas. La Carta fomenta la cooperación entre agencias espaciales y los operadores de satélites privados. Cada miembro se ha comprometido a comunicar información en aras de atenuar las repercusiones de los cataclismos, especialmente para los grupos humanos.

\section{PREVENCION DE RIESGOS}

Las imágenes satelitales de observación de la Tierra nos han demostrado que más del $70 \%$ de los desastres naturales tienen un origen meteorológico.

Las imágenes proporcionadas por los satélites Meteosat y MSG no solo sirven para realizar las cartas meteorológicas que presentan las cadenas de 
televisión en Europa, sino también para otras aplicaciones como ayuda del control del tráfico aéreo.

En cuanto a la prevención de incendios forestales, los satélites permiten definir de mejor manera el alcance logrado por el fuego, la monitorización de posibles rebrotes y determinar de mejor manera las áreas a supervisar.

Con respecto a los sismos y terremotos, actualmente los satélites tiene la misión de analizar la ionosfera de la Tierra en búsqueda de señales asociadas con la actividad sísmica, para según ello poder ver si es posible una predicción de los mismos.

\section{APLICACIONES ACTUALES}

Existen muchas aplicaciones actuales en los que la tecnología espacial es utilizada en beneficio del medio ambiente, entre estas aplicaciones podemos mencionar las siguientes:

\section{A. Seguimiento de animales marinos por ARGOS}

ARGOS es un sistema de colección y localización iniciado en 1978. Sus instrumentos están colocados en 5 satélites que giran alrededor de la tierra a una altura de $850 \mathrm{Km}$. Uno de sus objetivos científicos es el de estudiar y proteger algunas especies de animales.

El principio de funcionamiento es sencillo, el emisor es colocado sobre el animal y es alimentado por baterías o paneles solares, las medidas recolectadas son enviadas a los satélites y estas a su vez a las diferentes 60 estaciones terrenas en el mundo equipadas para tal fin.

ARGOS es el único sistema capaz de hacer el seguimiento de animales en medios extremos como la Antártica.

\section{B. La constelación RADARSAT}

Ha sido iniciada en 2005 por la Agencia Espacial Canadiense (CSA ASC) con 3 objetivos fundamentales: Monitoreo de los océanos, monitoreo del ecosistema y la gestión de desastres. Este proyecto tiene 5 fases: La primera que comenzó en el 2005 trata del estudio de factibilidad; la segunda fase empezó en el 2007 con los diseños preliminares; la fase 3 comenzó en el 2010 con el diseño más detallado; la cuarta fase empieza el 2012 con la construcción y los lanzamientos, el primer lanzamiento está previsto para el 2014 y 2 nuevos lanzamientos para el 2015; finalmente la fase 5 es la operación, colección y análisis de datos.

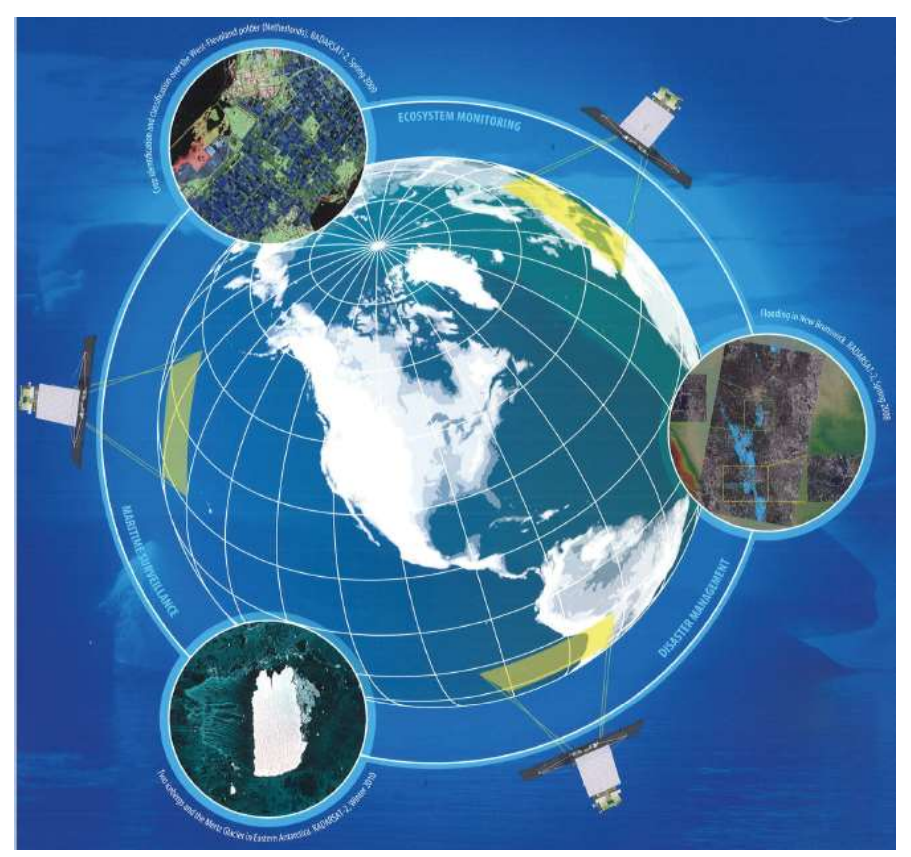

Figura 6. Constelación RADARSAT

\section{Contribución satelital a la vigilancia marítima}

El crecimiento constante de las actividades marítimas y el incremento de diferentes incidentes en los mismos, hace necesario el desarrollo de un medio de vigilancia y supervisión. Es por ello que utilizando los medios satelitales se ha desarrollado el Sistema de Identificación Automática (AIS).

\section{Misión BIOMASS}

La misión BIOMASS, es una misión de la ESA dentro de su programa Exploración de la Tierra (EE - Earth Explorer), la misión BIOMASS responde a la urgente necesidad de mejorar el mapeo de la biomasa global de la Tierra, ya que en la actualidad no existe ningún sistema espacial capaz de realizar dicha tarea con bastante precisión.

\section{CONCLUSIONES}

En definitiva, la tecnología aeroespacial es de gran ayuda para poder monitorear el medio ambiente y poder realizar distintas aplicaciones como las que se han mencionado en el presente artículo. Gracias a 
sus diferentes ventajas como lo son la accesibilidad, la globalización, la precisión, la cobertura, etc. La tecnología espacial se ha convertido en una herramienta muy importante para la toma de decisiones con respecto al cambio climático, deforestación, biodiversidad y todos aquellos temas que tiene que ver con la conservación de nuestro medio ambiente.

En nuestro Perú, el 27 de marzo de 2011 se ha anunciado la adquisición de un satélite de observación de la Tierra, lo cual significa que pronto contaremos con una herramienta muy útil para distintas áreas y es por ello que en el área medioambiental también ya se debe estar planificando una propuesta de análisis y aplicación de los datos que proporcionará dicho satélite peruano.

\section{REFERENCIAS}

[1] Centre National d'Etudes Spatiales, "L'Espace et l'Enviroment", Collection "De l'Espace pour la Terre", France, Julio. 2009, pp. 1-47.

[2] Centre National d'Etudes Spatiales, "Le CNES Comme Acteur Desgne du Developpement Durable", CNESMAG, France, $\mathrm{N}^{\circ} 42$, Julio. 2009, pp. 6.

[3] Centre National d'Etudes Spatiales, "AIS, une Contribution Satellitaire a la Surveillance Maritime", CNESMAG, France, $\mathrm{N}^{\circ}$ 46, Julio. 2010, pp. 15.

[4] Centre National d'Etudes Spatiales, "Biodiversité Espace et Preservation des Especes”, CNESMAG, France, $N^{\circ} 46$, Julio. 2010, pp. 38-39.

[5] Centre National d'Etudes Spatiales, 'L'Espace au Service de la Directive-cadre sur l'Eau", CNESMAG, France, $N^{\circ} 46$, Julio. 2010, pp. 54-55.

E-mail: avid.roman-gonzalez@ieee.org 